\title{
EFFECT OF FABRIC LAYERS ON THERMAL COMFORT PROPERTIES OF MULTILAYERED THERMAL PROTECTIVE FABRICS
}

\author{
Selin Hanife Eryuruk \\ Istanbul Technical University, Textile Technologies and Design Faculty, Textile Engineering Department, Istanbul, Turkey \\ E-mail: eryuruk@itu.edu.tr
}

\begin{abstract}
:
Thermal protective clothings are produced from multilayered textile materials. Fabric layers need to allow enough evaporation of perspiration, ventilation, and also thermal protection from fire. This study aimed to evaluate the effects of different fabric layers and their different combinations on the thermal properties of multilayered fabric samples. Three-layered fabric combinations were created using two types of outer shell fabrics, four types of moisture barrier fabrics with membrane, and two types of thermal barrier fabrics. Sixteen different fabric combinations that simulate three-layered thermal protective clothing were studied. As a result of the study, it was found that thermal and moisture comfort properties were significantly affected by different fabric layers.
\end{abstract}

\section{Keywords:}

Thermal protective fabrics; multilayered fabric structure; thermal comfort

\section{Introduction}

Human comfort mainly depends on physical, physiological, and neurological processes between clothing and environment. Physical processes provide physical stimuli to the body considering heat and moisture transfer between clothing and environment. Thermal and moisture sensations are very important and have a significant impact on the perception of comfort in various environments [1,2]. Moreover, material properties, style, fit, size, and drape of garments influence heat and moisture transfer capacities. Especially, fiber type, fabric composition, and the number of layers play a significant role in heat and moisture transport properties of fabrics [3-7].

Thermal protective garments are produced using special multilayered fabrics that are bulky and heavy. Protection together with comfort is a very important subject for people's performance and health. These garments must provide sufficient thermal isolation from heat and also permit enough thermal and moisture comfort for the working performance. A successful protective clothing must allow the functions of the body as well as protect it from environmental hazards and agents. Clothing provides a microclimate between body and the external environment. The thermoregulatory responses of the body, heat transfer rate, and vapor permeation properties of the clothing determine the microclimate. Thermal protective clothing must be evaluated considering specified standards and specifications, risk factors, safety requirements, thermal performance properties, and comfort properties [8-16]. Moreover, material compositions and design influence the thermal protection and moisture transmission properties of protective garments [17-19].

Thermal protective clothing's heat and moisture transfer capacities were affected by style, fit, size, and drape of garments beside material properties [3]. According to Chung and Lee's clothing system, design and material layers must be chosen carefully to balance protection and comfort together [13]. Fu et al. tested two kinds of protective clothings with different vapor permeabilities to study the design influence on protective properties [20]. They found that the time required to form the microenvironment is greatly influenced by the internal and external moisture difference and the level of vapor permeability. Wang et al. analyzed the overall comfort level of the clothing ensembles considering the effect of different inner clothing items combined with the firefighters' protective clothing using wear trial method [21]. They found significant differences in the thermal, moisture, and clingy sensations of various clothing ensembles at $28^{\circ} \mathrm{C}$ (warm), but they were not significant under the temperature of $15^{\circ} \mathrm{C}$ (cool), except for clingy sensation. Lawson measured the thermal conductivity values of 10 different materials that were used in the production of firefighters' protective clothing [22]. According to Lawson, thermal performance of firefighters' protective clothing was primarily based on the thermophysical properties of the materials and the insulating airspace that was provided by the garment design. Eryürük selected and evaluated two different types of firefighter uniforms and analyzed their thermal comfort properties [23].

A serious potential concern for thermal protective clothing is the temperature transmission through the fabric which is tested by the thermal protective performance (TPP) tests. Kutlu and Cireli used TPP test for thermal analysis of singlelayer and two- and three-layer fabric constructions before and after certain washing cycles [24]. Cui and Zhang analyzed 16 assemblies for firefighter protective clothing and concluded that outer heat-resistant fabric and the moisture barrier fabric had significant effects on the TPP rating of assemblies. Furthermore, moisture barrier played a significant role in the water vapor transmission rate (WVTR) of assemblies, and 
WVTR of three-layer assemblies is much lower than that of single-layer material [25].

In the literature, there are many studies about the thermal comfort properties of casual wear garments. Considering thermal protective garments, it is clearly seen that researchers mainly focused on TPP tests, heat and mass transfer properties, thermal manikin, sweating torso tests, and the effect of different design features. Small studies focused only on the moisture transmission properties of thermal protective garments. As a result, it was concluded that there is a need to evaluate the effects of different fabric combinations on the thermal comfort properties of thermal protective fabrics. Two outer shell fabrics, four moisture barrier fabrics with membrane, and two thermal barriers were selected to evaluate thermal comfort properties. These fabrics were combined with each other, and 16 fabric combinations were obtained. Three-layer fabric structures were tested and compared to the single-layer fabric behavior. The main aim was to analyze the effects of different fabric combinations on the thermal comfort properties of the protective fabrics.

\section{Materials and methods}

\subsection{Materials}

For material selection, investigations were conducted including literature review and interview with the industry owners. In this

Table 1. Characteristics of fabrics study, all material types were deeply investigated and samples were selected from the standard materials that are mostly used for thermal protection and supplied from a well-known fabric brand in the world.

Two different outer shell fabrics, four different moisture barrier fabrics, and two types of thermal barrier fabrics made of paraaramid and meta-aramid blend FR materials were selected for the experiments as summarized in Tables 1-3. Meta-aramid outer shell tough fabric had 2/1 twill and polybenzimidazole (PBI) fabric ripstop weave structure. Moisture barrier fabrics were laminated using hot-melt lamination technology. Waterjet nonwoven fabric, $1 \backslash 1$ plain weave woven fabric, and single jersey knitted fabrics were used as the moisture barrier fabrics.

\subsection{Methods}

Thermal properties of textiles are mostly evaluated with thermal resistance, thermal conductivity, and thermal absorptivity analyses. Alambeta instrument was used to test the thermal properties of the fabrics. The device is a computer-controlled instrument designed for the measurement of the basic static and dynamic thermal characteristics of textiles [26]. It measures the thermal conductivity, thermal diffusion, thermal absorptivity, thermal resistance values, and the material thickness. The Alambeta instrument simulates the dry human skin. Its working principle is based on the mathematical processing of time course of heat flow passing through the fabric, and heat flow is created by the temperature difference between hot top measuring head

\begin{tabular}{|c|c|c|}
\hline Layers & Fabrics & Outer shell fabric \\
\hline First layer & Moisture barrier fabric \\
\hline Second layer & Thermal barrier fabric \\
\hline Third layer & OUTER FABRIC \\
\hline
\end{tabular}

Table 2. Fabric properties

\begin{tabular}{|c|c|c|c|c|}
\hline $\begin{array}{c}\text { Fabric } \\
\text { code }\end{array}$ & Fabric type & $\begin{array}{c}\text { Mass per unit area } \\
\left(\mathbf{g} / \mathbf{m}^{\mathbf{2}}\right)\end{array}$ & $\begin{array}{c}\text { Thickness } \\
(\mathbf{m m})\end{array}$ & Layer type \\
\hline X1 & Meta-aramid outer shell tough & 200 & 0.369 & Outer shell \\
\hline X2 & $40 \%$ PBI/60\% para-aramid & 200 & 0.393 & Outer shell \\
\hline Y1 & PU membrane laminated to FR knitted fabric & 90 & 0.270 & Moisture barrier \\
\hline Y2 & PU membrane laminated to FR knitted fabric & 150 & 0.435 & Moisture barrier \\
\hline Y3 & PU membrane laminated to FR nonwoven & 120 & 0.726 & Moisture barrier \\
\hline Y4 & PU membrane laminated to FR woven fabric & 150 & 0.309 & Moisture barrier \\
\hline Z1 & Aramid felt quilted to aramid/viscose FR fabric & 175 & 1.635 & Heat barrier \\
\hline Z2 & Aramid felt quilted to aramid/viscose FR fabric & 200 & 1.911 & Heat barrier \\
\hline
\end{tabular}

Abbreviation: PBI, polybenzimidazole. 
Table 3. Multilayered fabric combinations

\begin{tabular}{|c|c|c|c|}
\hline $\begin{array}{c}\text { Sample } \\
\text { number }\end{array}$ & Fabric code & $\begin{array}{c}\text { Sample } \\
\text { number }\end{array}$ & Fabric code \\
\hline 1 & $\mathrm{X} 1 \mathrm{Y} 1 \mathrm{Z1}$ & 9 & $\mathrm{X} 2 \mathrm{Y} 1 \mathrm{Z1}$ \\
\hline 2 & $\mathrm{X} 1 \mathrm{Y} 2 \mathrm{Z} 1$ & 10 & $\mathrm{X} 2 \mathrm{Y} 2 \mathrm{Z} 1$ \\
\hline 3 & $\mathrm{X} 1 \mathrm{Y} 3 \mathrm{Z} 1$ & 11 & $\mathrm{X} 2 \mathrm{Y} 3 \mathrm{Z} 1$ \\
\hline 4 & $\mathrm{X} 1 \mathrm{Y} 4 \mathrm{Z} 1$ & 12 & $\mathrm{X} 2 \mathrm{Y} 4 \mathrm{Z1}$ \\
\hline 5 & $\mathrm{X} 1 \mathrm{Y} 1 \mathrm{2} 2$ & 13 & $\mathrm{X} 2 \mathrm{Y} 1 \mathrm{Z2}$ \\
\hline 6 & $\mathrm{X} 1 \mathrm{Y} 2 \mathrm{2} 2$ & 14 & $\mathrm{X} 2 \mathrm{Y} 2 \mathrm{2} 2$ \\
\hline 7 & $\mathrm{X} 1 \mathrm{Y} 3 Z 2$ & 15 & $\mathrm{X} 2 \mathrm{Y} 3 \mathrm{2} 2$ \\
\hline 8 & $\mathrm{X} 1 \mathrm{Y} 4 \mathrm{2} 2$ & 16 & $\mathrm{X} 2 \mathrm{Y} 4 \mathrm{Z} 2$ \\
\hline
\end{tabular}

and cold bottom baseplate $[26,27]$. During the measurements, backsides of the single-layer fabrics were placed facing upwards for each sample. Sixteen fabric combinations were obtained using three fabric layers considering both garment design requirements and fabric faces. Respectively, outer shell fabric, moisture barrier fabric, and thermal barrier fabric were placed from outside to inside. Backsides of the three-layered fabric structures were placed looking to the hot top plate, and front sides of the layered fabric structures were placed looking to the lower baseplate that simulates real wearing conditions.

Permetest instrument was also used to measure water vapor resistance and water vapor permeability according to the ISO 11092:2014 (sweating guarded hotplate test) standard [28].

The samples were conditioned for 24 hours before tests. Tests were carried out five times under standard atmospheric conditions, $20 \pm 2{ }^{\circ} \mathrm{C}$ temperature and $65 \pm 2 \%$ relative humidity. Statistical analyses were conducted using IBM SPSS 25 statistic program.

\section{Results and discussion}

Thermal comfort test results of fabrics are shown in Figures 1-12. It is important to understand single-layer fabric's results to understand three-layer fabric assemblies' thermal comfort properties. Moreover, fabric layer types, thicknesses, and weight values are important parameters that must be considered.

Figures 1 and 2 show the thermal conductivity test results of single- and multilayer fabric structures. Thermal conductivity $(I)$ is evaluated as the quantity of heat that passes in unit time through the unit area of a unit thickness when a unit difference of temperature exists between its faces [29]. As the singlelayer $\mathrm{PBI}$ outer shell (X2) had higher thermal conductivity value, multilayered fabric structures with outer shell $\mathrm{X} 2$ had higher thermal conductivity performances. As the thermal conductivity values of knitted moisture barrier fabric Y2 and woven fabric $Y 4$ had higher values, higher conductivity values for these fabric combinations were also obtained. Aramid that felt quilted to aramid/viscose FR fabrics had higher thickness values compared to the outer shell and moisture barrier fabrics. Moreover, Z1 and Z2 fabrics had nearly similar and quite high thermal conductivity results, and this had a great influence on the multilayered fabric samples. As shown in figures, the best thermal conductivity performances were obtained for the fabric combinations of $X 2 Y 2 Z 1$ and $X 2 Y 4 Z 1$. Considering multilayered fabric combinations with outer shell X1, X1Y2Z1 and X1Y4Z1 had higher thermal conductivity values than other fabrics. Here, we can conclude that thermal layer and outer shell fabrics had a significant role in thermal conductivity results. These fabrics had high and very close thermal conductivity results, so we have obtained very similar and high thermal conductivity results for multilayered fabric structures (Figure 2). This may be due to the fact that thermal conductivity of fiber is higher than the thermal conductivity of the entrapped air as stated in the previous studies [27-29]. Multilayered fabric combinations had high tightness values that increased the amount of fiber in a specific area of the fabric and also the thermal conductivity values.

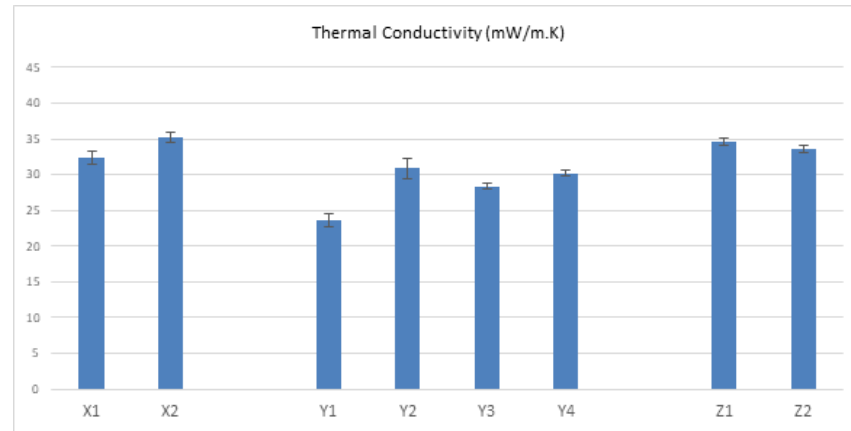

Figure 1. Thermal conductivity of single-layered fabrics

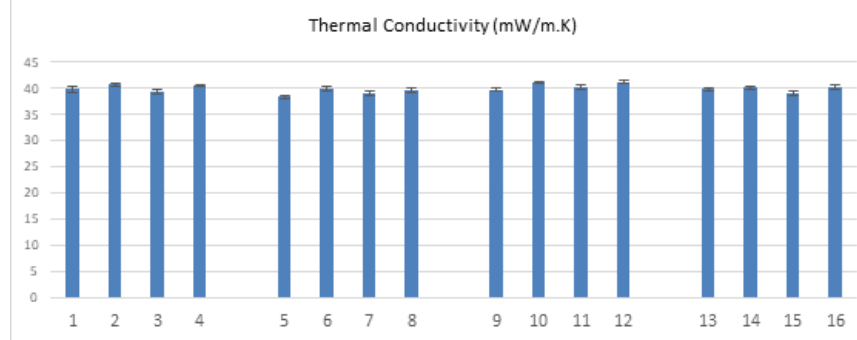

Figure 2. Thermal conductivity of multilayered fabrics

Thermal resistance $\left(R_{\mathrm{ct}}\right)$ represents thermal insulation property of a fabric; the higher the thermal resistance, the higher the thermal insulation capacity of a fabric. As it can be seen from the single-layer fabric results, although the thermal resistance values were very close to each other for outer fabrics and moisture barrier fabrics, there were slight differences for thermal barrier fabrics. Only fabric Y3 (PU membrane laminated to FR nonwoven) had higher thermal resistance value because of the porous structure of nonwoven fabric. Z1 and Z2 fabrics had very high thermal resistance values compared to other fabric types (Figures 3-4). The effects of these fabrics on the thermal resistance behavior of multilayered fabrics are shown in Figure 4. As a result, X1Y3Z1, X1Y3Z2, X2Y3Z1, X2Y3Z2, and $X 2 Y 4 Z 2$ fabrics had higher thermal resistance values. As shown in Figure 4, thermal barrier fabric $(Z)$ had a high influence, and 
moisture barrier fabrics had a specifying effect on increasing and decreasing behavior in the thermal resistance values of multilayered fabrics. According to the experimental results, thermal resistance values of fabrics increased depending on the thickness of the fabric structure. We have found a strong relationship between the value of the thermal resistance of materials and their thicknesses (Table 4) that are similar to the findings of Matusiak [27]. The reason why thickness increases thermal resistance is that air layer inside the thermal barrier $(Z)$ fabrics is higher because of its bulky and thick structure, as a result, it becomes a heat transfer-resistant layer as stated in the previous results $[30,31]$.

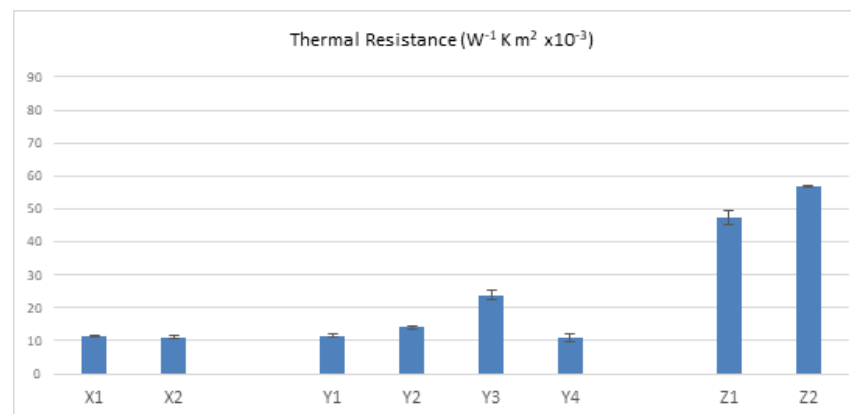

Figure 3. Thermal resistance of single-layered fabrics

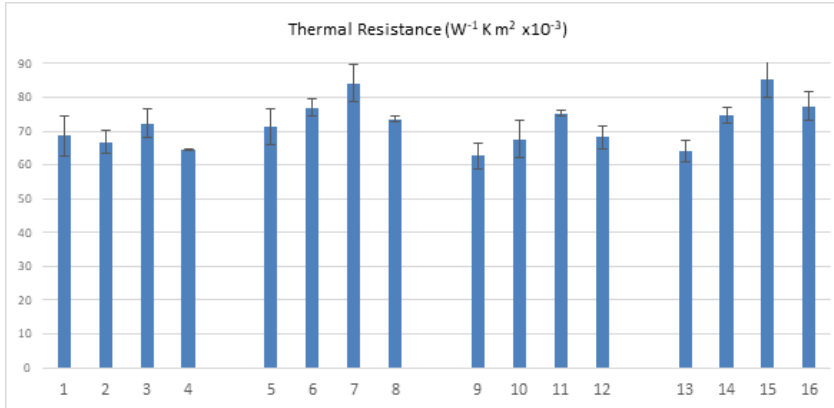

Figure 4. Thermal resistance of multilayered fabrics

Thermal diffusion (a) is a very important property considering comfort tests. It is an ability related to the heat flow through the air in the fabric structure; the higher the thermal diffusion, the faster the heat propagation. Higher thermal diffusion value is mainly related to bulky fabric structures because of a large amount of air inside the structure. The highest value of the thermal diffusion was observed for the $Z 2$ fabric that has more bulky structure than Z1 with its higher thickness and a large amount of air in the structure (Figure 5). Nonetheless, the thermal diffusion values of the outer shell $(X)$ and moisture barrier $(Y)$ fabrics seemed to be lower than the thermal diffusion values of the thermal barrier fabrics. Considering the thermal diffusion characteristics of three-layered fabrics, it was seen that outer shell $(X)$ and moisture barrier $(Y)$ fabrics have played a significant role in the multilayered fabric structures (Figure 6). Although thermal barrier ( $Z$ ) fabrics had very high thermal diffusion values, it was observed that outer and moisture barrier fabrics ( $X$ and $Y$ ) had very low thermal diffusion values, and this gave rise to a barrier effect in the multilayered fabric structures. Thus, thermal diffusion values of multilayered structures were obtained very close to each other, and lower values were obtained just as the $X$ and $Y$ layers (Figure 6). This is an important result that must be taken into account during the design of multilayered fabric constructions.

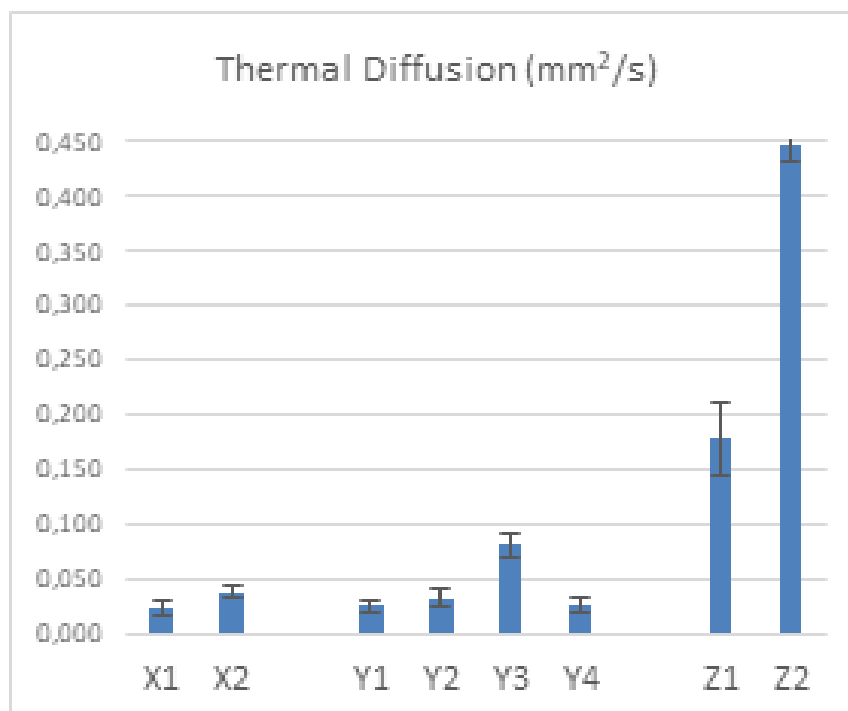

Figure 5. Thermal diffusion of single-layered fabrics
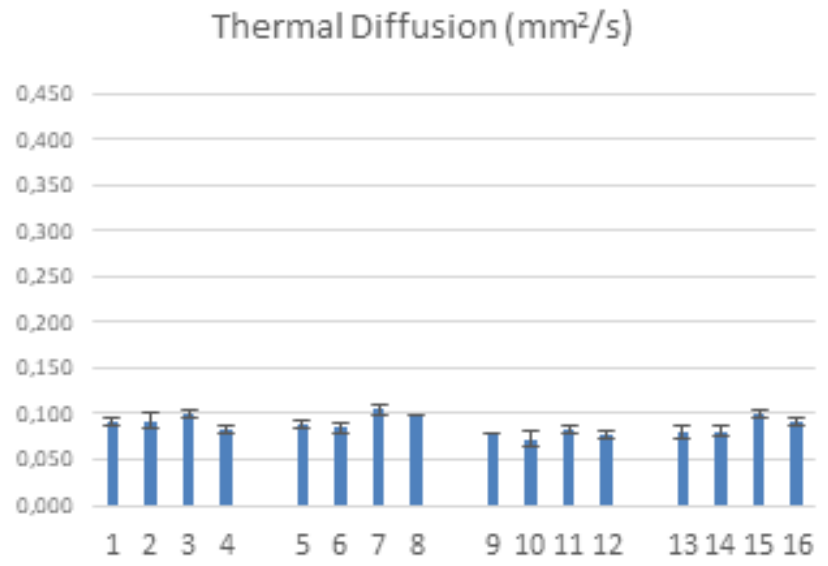

Figure 6. Thermal diffusion of multilayered fabrics

Thermal absorptivity $(b)$ gives the warm-cool feeling of fabrics. Lower thermal absorptivity means higher warm feelings. As shown in Figure 7, fabrics with outer shell X1 had higher thermal absorptivity than the fabrics with outer shell X2. Moisture barrier fabrics $Y 2$ and $Y 4$ had higher thermal absorptivity values, and as a result all multilayered fabric combinations with $\mathrm{Y} 2$ and $\mathrm{Y} 4$ had higher values. Moreover, thermal barrier fabrics Z1 and Z2 had lower thermal absorptivity values. Having lower thermal absorptivity values led to a warmer feeling at the beginning of skin contact. Thermal absorptivity is mainly related to the surface characteristics such as surface smoothness. Smoother fabric surface increases the area of contact and the heat flow, thereby creating a cooler feeling [29]. Thermal barrier fabric structures have rough surfaces and peak and valley patterns on the fabric surface, and it decrease the contact area and so the flow of the heat. Since thermal barrier fabrics have a direct contact with the skin, they had a significant role in thermal absorptivity results of multilayered fabric structures (Figure 8). 


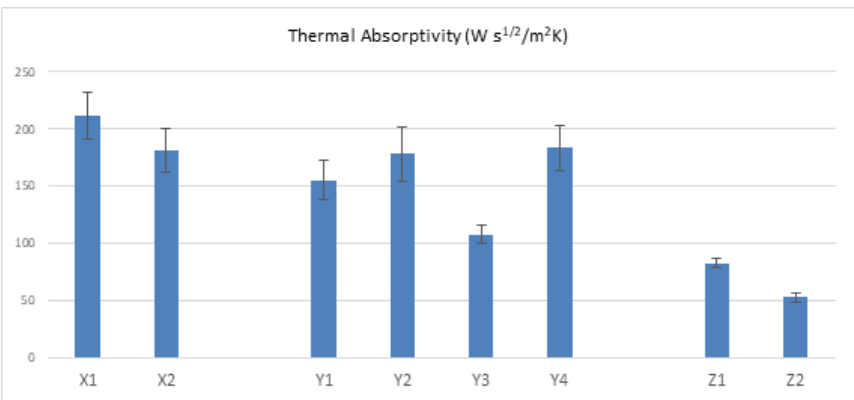

Figure 7. Thermal absorptivity of single-layered fabrics

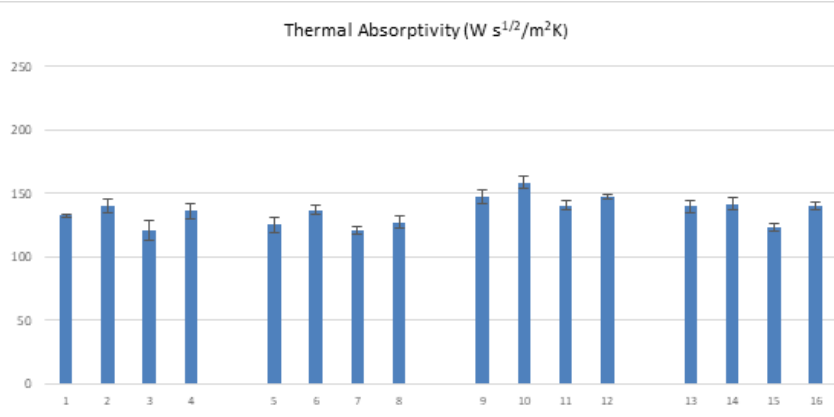

Figure 8. Thermal absorptivity of multilayered fabrics

Water vapor resistance is the ability of a fabric to allow moisture vapor to be transmitted through it and is called as breathability. This is a very important indicator showing the comfort level of a clothing. Figure 9 shows that X1, Y2, Y4, and $Z 2$ fabrics had higher water vapor resistance values. Figure 10 shows the water vapor resistance of multilayered fabrics. As shown in the figure, $R_{\text {et }}$ values are highly dependent on the moisture barrier fabrics (X1Y4Z1, X1Y4Z2, X2Y4Z1, and $\mathrm{X} 2 \mathrm{Y} 4 \mathrm{Z2}$ ). Moisture barrier fabrics had a considerable effect on water vapor resistance values. It is also clear that as the number of fabric layers was increased, water vapor resistance values also increased (Figure 10). As stated by Zhiying et al., moisture barrier fabric had a significant effect on moisture transmission properties; therefore, overall moisture distribution in multilayered protective clothing can be influenced by using defined combinations of hydrophilic and hydrophobic textile layers [18]. As shown in the figure, water vapor resistance increases with the increment in material thickness and air entrapped in the fabric, and this result is exactly similar to the result obtained by Havenith [32].

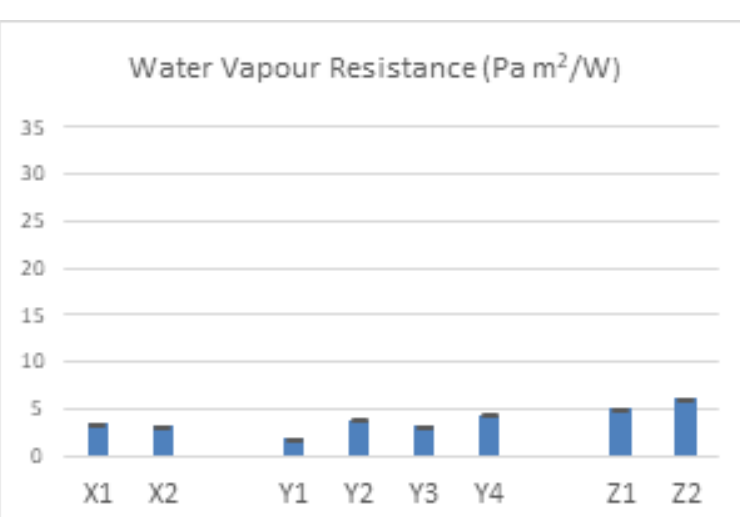

Figure 9. Water vapor resistance of single-layered fabrics

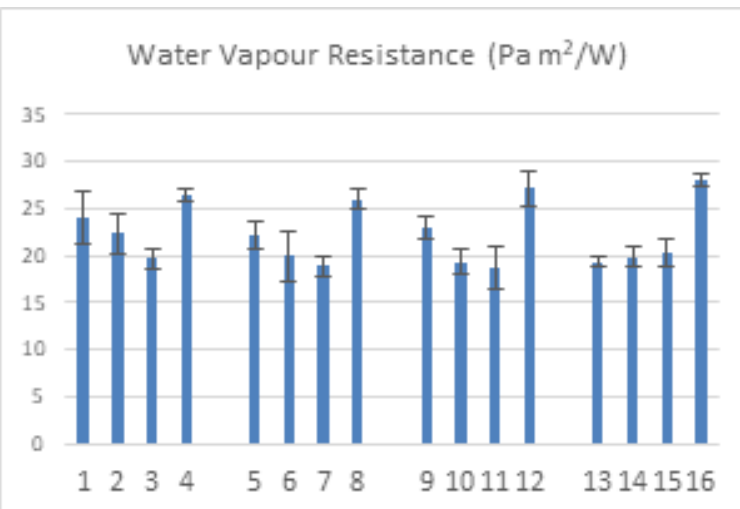

Figure 10. Water vapor resistance of multilayered fabrics

As stated by Shekar et al., the presence of moisture to an extent of $10-20 \%$ would cause a reduction in thermal resistance to an extent as high as $50 \%$, so this must also be considered during the comfort evaluations [33]. For this reason, water vapor permeability of multilayered fabrics must be evaluated for thermal comfort evaluations. Water vapor permeability is the ability of a material to allow water vapor to pass through it. It has a reverse relationship with water vapor resistance. Water vapor permeability depends significantly on the moisture barrier fabrics (Figure 11 and 12). As shown in Figure 11, X2, $Y 1$, and $Z 1$ fabrics had higher permeability values. Multilayered fabric structures of X1Y4Z1, X1Y4Z2, X2Y4Z1, and X2Y4Z2 had lower levels of permeability values. In addition, as shown in Figure 12, as the number of layers increased, water vapor permeability values decreased compared to single-layer fabrics.

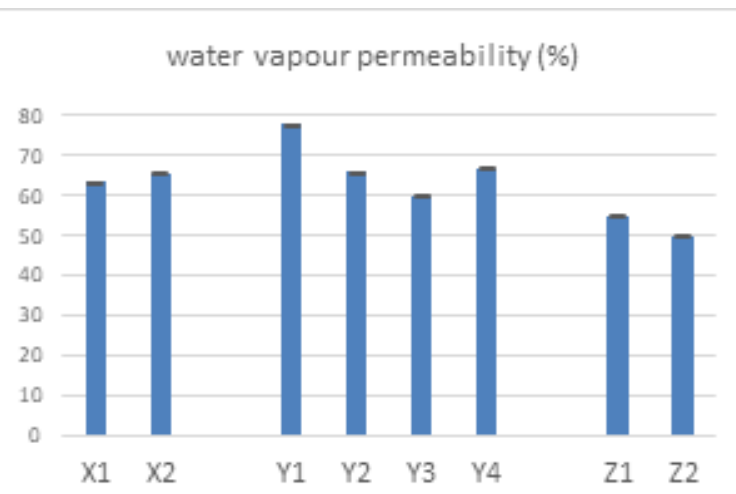

Figure 11. Water vapor permeability of single-layered fabrics

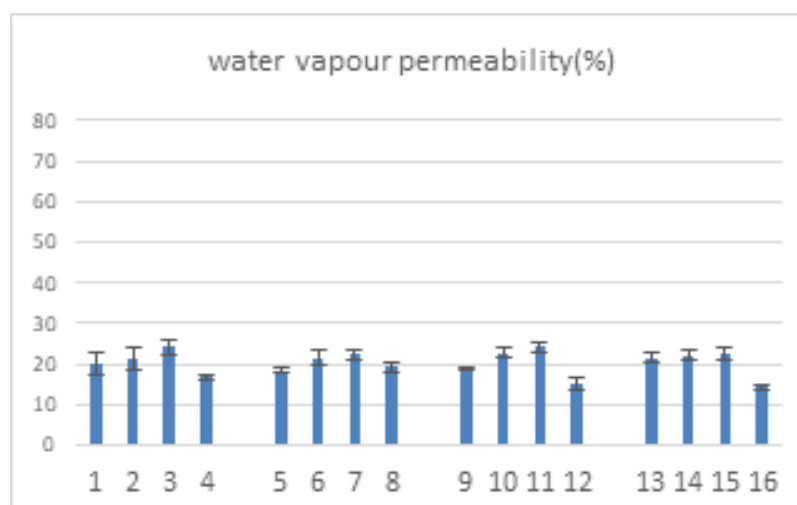

Figure 12. Water vapor permeability of multilayered fabrics

We have found high correlation values between thermal 
conductivity, thermal diffusivity, thermal absorptivity, thermal resistance, water vapor permeability, and water vapor resistance (Table 4). A strong relationship was observed between the value of the thermal resistance of materials and their thickness values.

Table 4. Correlation values of variables

\begin{tabular}{|c|c|}
\hline Variable & Correlation \\
\hline $\begin{array}{c}\text { Thermal conductivity and thermal } \\
\text { absorptivity }\end{array}$ & 0.599 \\
\hline Thermal diffusion and thermal absorptivity & -0.748 \\
\hline Thermal resistance and thickness & 0.960 \\
\hline $\begin{array}{c}\text { Water vapor permeability and water vapor } \\
\text { resistance }\end{array}$ & -0.890 \\
\hline
\end{tabular}

The influences of fabric layer types on the thermal comfort characteristics were evaluated using one-way analysis of variance (ANOVA) statistical analysis (Table 5). When outer shell fabrics were considered, it was obtained that there is a significant difference between the means of thermal conductivity, thermal diffusion, and thermal absorptivity values. Moisture barrier fabrics had been found to influence on all comfort measurements. As it was expected, thermal barrier fabrics had an effect on all the thermal comfort measurements. The results are highly similar to the test results mentioned earlier.

At the final step of evaluation, regression analyses were made between thermal properties and fabric layers. Thermal properties of multilayered fabrics were defined as dependent variables $\left(I, R_{\mathrm{ct}}, b, a\right)$, and thermal properties of single fabric layers were defined as independent variables (X, Y, Z). Linear regression analysis was applied to the measured values and the best fit equations were obtained using IBM SPSS 25 statistic program. The best regression equations and significant levels for each thermal property are given in Table 6 . As it is seen, the results were found to be highly correlated with the experimental data.

\section{CONCLUSIONS}

Thermal protective clothings are produced from multilayered textile materials, and the protection together with comfort is very important for the working efficiency of firefighters. In this study, the effects of different fabric layers and their different combinations on the thermal comfort properties of multilayered fabric samples that are used to produce thermal protective
Table 5. ANOVA test results

\begin{tabular}{|c|c|c|c|}
\hline & df & $\mathbf{F}$ & Sig. \\
\hline \multicolumn{4}{|c|}{ Factor: outer layer } \\
\hline Thermal conductivity & 47 & 5.744 & 0.021 \\
\hline Thermal diffusion & 47 & 10.426 & 0.002 \\
\hline Thermal absorptivity & 47 & 13.167 & 0.001 \\
\hline \multicolumn{4}{|c|}{ Factor: moisture barrier fabrics } \\
\hline Thermal conductivity & 47 & 7.91 & 0.000 \\
\hline Thermal diffusion & 47 & 4.735 & 0.006 \\
\hline Thermal absorptivity & 47 & 5.984 & 0.002 \\
\hline Thermal resistance & 47 & 7.808 & 0.000 \\
\hline Water permeability & 47 & 49.472 & 0.000 \\
\hline$R_{\mathrm{et}}$ & 47 & 26.951 & 0.000 \\
\hline \multicolumn{4}{|c|}{ Factor: thermal barrier fabrics } \\
\hline Thermal conductivity & 47 & 14.809 & 0.000 \\
\hline Thermal diffusion & 47 & 5.371 & 0.025 \\
\hline Thermal absorptivity & 47 & 4.844 & 0.033 \\
\hline Thermal resistance & 47 & 15.386 & 0.000 \\
\hline
\end{tabular}

Abbreviation: ANOVA, analysis of variance.

clothing were studied.

It is apparent from the results that thermal comfort properties of thermal protective fabrics are highly dependent on the type and combination of multilayered fabric samples. Outer shell fabrics are especially very important to prevent the wearer from thermal hazards; in addition, they influence the thermal comfort level of the protective uniforms. As a result of experimental studies, it was found that regarding thermal conductivity especially outer shell and thermal barrier fabrics had a significant role. Thermal conductivity of fiber is higher than the entrapped air so tight fabric structures with more fibers and less air had more thermal conductivity values as outlined in the previous studies $[28,29]$. Considering the thermal diffusion characteristics of garments, it was obtained that outer shell and moisture barrier fabrics had played a significant role. The area of contact between fabric and skin had a great influence on thermal absorptivity so thermal layer had an important role in thermal absorptivity. Thickness was also found to have a statistically significant influence on the thermal resistance of fabrics. Moisture barrier fabrics are mainly important for moisture management properties of

Table 6. The regression equations between thermal properties

\begin{tabular}{|c|c|c|c|}
\hline Thermal properties & Regression equations & Sig. & $\mathbf{R}^{2}$ \\
\hline Thermal conductivity & $I=4.363+0.167 \mathrm{X}+0.143 \mathrm{Y}+0.750 Z$ & 0.014 & 0.576 \\
\hline Thermal resistance & $R_{\mathrm{ct}}=21.286+0.776 \mathrm{Y}+0.750 \mathrm{Z}$ & 0.000 & 0.708 \\
\hline Thermal absorptivity & $b=163.775-0.403 \mathrm{X}+0.198 \mathrm{Y}+0.310 \mathrm{Z}$ & 0.000 & 0.855 \\
\hline Thermal diffusion & $a=0.094-0.723 \mathrm{X}+0.209 \mathrm{Y}+0.023 \mathrm{Z}$ & 0.002 & 0.703 \\
\hline
\end{tabular}


fabrics. It was found that different moisture barrier materials had great influences on water vapor permeability and water vapor resistance test results.

In this study, it was aimed to analyze thermal comfort properties of thermal protective fabrics by analyzing and comparing the single-layer behavior with the multilayer fabric performances. As a conclusion, it was found that outer shell, moisture barrier, and thermal barrier fabrics had a significant role in the thermal comfort behavior. Results of this study could be used by textile engineers and academic researchers to analyze the thermal comfort behaviors of multilayered protective fabrics for different purposes. On the other hand, it should be taken into account that the above mentioned conclusions are only valid for the materials selected for this study. Further studies are still required to certify these conclusions with different types of fabrics. Moreover, more work is needed to evaluate thermal protective tests together with comfort analyses.

\section{ACKNOWLEDGEMENTS}

The author would like to thank Kıvanç Tekstil A.Ş., Turkey, for their fabric support.

\section{References}

[1] Li, Y. (2001). The science of clothing comfort. Textile Progress. 31(1-2), 1-35.

[2] Li, Y. (2005). Perceptions of temperature, moisture and comfort in clothing during environmental transients. Journal Ergonomics, 48(3), 234-248.

[3] Mah, T., Song, G. W. (2010). Investigation of the contribution of garment design to thermal protection. Part 2:Instrumented female mannequin flash-fire evaluation system. Textile Research Journal, 80, 1473-1487.

[4] Rossi, R. M., Gross, R., May, H. (2004). Water vapor transfer and condensation effects in multilayer textile combinations. Textile Research Journal, 74(1), 1-6.

[5] Schneider, A. M., Hoschke, B. N., Goldsmith, H. J. (1992). Heat transfer through moist fabrics. Textile Research Journal, 62(2), 61-66.

[6] Zhu, L., Wang, X., Blanchonette, I., Naebe, M. (2017). Thermal comfort properties of bifacial fabrics. Textile Research Journal, 87(19), 2307-2313.

[7] Sun, C., Fan, J. (2017). Comparison of clothing thermal comfort properties measured on female and male sweating manikins. Textile Research Journal, 87(18), 2214-2223.

[8] Raimundoa, A. M., Figueiredo, A. R. (2009). Personal protective clothing and safety of firefighters near a high intensity fire front. Fire Safety Journal, 44(4), 514-521.

[9] Teunissena, L. P. J., Wang, L. C., Chou, S. N. (2014). Evaluation of two cooling systems under a firefighter coverall. Applied Ergonomics, 45(6), 1433-1438.

[10] Levels, K., de Koning, J. J., Mol, E., Foster, C., Daanen, H. A. (2014). The effect of pre-warming on performance during simulated firefighting exercise. Applied Ergonomics, 45(6), 1504-1509.
[11] Son, S. Y., Bakri, I., Muraki, S., Tochihara, Y, (2014). Comparison of firefighters and non-firefighters and the test methods used regarding the effects of personal protective equipment on individual mobility. Applied Ergonomics, 45(4), 1019-1027.

[12] Kong, P. W., Suyama, J., Hostler, D. (2013). A review of risk factors of accidental slips, trips, and falls among firefighters. Safety Science, 60, 203-209.

[13] Chung, G. -S., Lee, D. H. (2005). A study on comfort of protective clothing for firefighters. Elsevier Ergonomics Book Series, 3, 375-378.

[14] Jiang, Y. Y., Yanai, E., Nishimura, K., Zhang, H., Abe, $N$., et al. (2010). An integrated numerical simulator for thermal performance assessments of firefighters' protective clothing. Fire Safety Journal, 45(5), 314-326.

[15] Hoschke, B. N. (1981). Standard and specifications for firefighters' clothing. Fire Safety Journal, 4(2), 125-137.

[16] Kim, J. H., Williams, W. J., Coca, A., Yokota, M. (2013). Application of thermoregulatory modeling to predict core and skin temperatures in firefighters. International Journal of Industrial Ergonomics, 43(1), 115-120.

[17] Li, J., Barker, R. L., Deaton, A. S. (2007). Evaluating the effects of material component and design feature on heat transfer in firefighter turnout clothing by a sweating manikin. Textile Research Journal, 77(2), 59-66.

[18]Zhiying, C, Yanmin, W, Weiyuan, Z. (2010). Thermal protective performance and moisture transmission of firefighter protective Clothing based on orthogonal design. Journal of Industrial Textiles, 39(4), 347-356.

[19] Keiser, C., Becker, C. Rossi, R. M. (2008). Moisture transport and absorption in multilayer protective clothing fabrics. Textile Research Journal, 78(7), 604-613.

[20] Fu, M., Weng, W., Han, X. (2013). Effects of moisture transfer and condensation in protective clothing based on thermal manikin experiment in fire environment. Procedia Engineering, 62, 760-768.

[21] Wang, Y., Zhang, Z., Li, J., Zhua, G. (2013). Effects of inner and outer clothing combinations on firefighter ensembles' thermal and moisture related comfort levels. The Journal of The Textile Institute, 104(5), 530-540.

[22] Lawson, J. R. (2005). Estimates of thermal conductivity for unconditioned and conditioned materials used in fire fighters' protective clothing. National Institute of Standards and Technology, NISTIR, 7282, 71.

[23] Eryürük, S. H. (2016). Analysis of thermal properties of firefighter's protective clothings. Tekstil ve Konfeksiyon, 26(3), 270-279.

[24]Kutlu, B., Cireli, A. (2005). Thermal analysis and performance properties of thermal protective clothing. Fibers \& Textiles in Eastern Europe, 13(3), 58-62.

[25] Cui, Z., Zhang, W. (2009). Study of the effect of material assembly on the moisture and thermal protective performance of firefighter clothing. Fibres \& Textiles in Eastern Europe, 17(6) (77), 80-83.

[26] Hes, L., De Araujo, M., Djulay, V. (1996). Effect of mutual bonding of textile layers on thermal insulation and thermal contact properties of fabric assemblies. Textile Research Journal, 66, 245-250. 
[27] Matusiak, M., (2006). Investigation of the thermal insulation properties of multilayer textiles. Fibres \& Textiles in Eastern Europe, 14(5) (59), 98-102.

[28] ISO 11092:2014. (2014). Textiles - physiological effects - measurement of thermal and water-vapour resistance under steady-state conditions (sweating guarded-hotplate test).

[29] Ramachandran, T., Manonmani, G., Vigneswaran, C. (2010). Thermal behavior of ring and compact-spun yarn single jersey, rib and interlock knitted fabrics. Indian Journal of Fibre \& Textile Research, 35, 250-257.
[30] Sabir, E. C., Kadem, F. D. (2016). Comfort and performance properties of raised and laminated denim fabrics. Fibres \& Textiles in Eastern Europe, 24, 5(119), 88-94.

[31] Ukponmwan, J. O. (1993). The thermal insulation properties of the fabrics. Textile Progress, 24(4), 1-54

[32] Havenith, G. (2002). The interaction of clothing and thermoregulation. Exogenous Dermatology, 1(5), 221-230.

[33] Shekar, I., Kasturiya, R. N., Raj, H., Nigam, S. (2001). Influence of wool-synthetic fibre blends on thermal insulation. Indian Journal of Fibre and Textile Research, 26, 287-295. 